\title{
NOTE
}

\section{Severe rainstorms in the Vidarbha subdivision of Maharashtra State, India}

\author{
B. D. Kulkarni *, S. Nandargi \\ Indian Institute of Tropical Meteorology, Dr. Homi Bhabha Road, Pune 411008, India
}

\begin{abstract}
This paper discusses the results of Depth-AreaDuration (DAD) analysis of the 8 most severe rainstorms that affected the Vidarbha subdivision of Maharashtra State, India, during the 100 yr period from 1891 to 1990 . It was found from this analysis that rainstorms in June 1908, July 1930 and August 1912 yielded greater raindepths for smaller areas, i.e. $\leq 1000 \mathrm{~km}^{2}$ and $\leq 25000 \mathrm{~km}^{2}$, and that the August 1986 rainstorm yielded greater raindepths for all the larger areas, for measurement periods of 1 to 3 days. The DAD raindepths of these severe rainstorms for different durations will be useful for the design storm estimates of different water resources projects in the Vidarbha region, as well as for checking the spillway capacity of existing dams.
\end{abstract}

KEY WORDS: Rainstorm - Depth-Area-Duration (DAD) Probable maximum precipitation (PMP)

1. Introduction. Dhar et al. (1989) and Kulkarni (1991) have studied severe rainstorms in Maharashtra State, India. Their studies indicate that severe rainstorms here are mostly confined to the Vidarbha region (see Fig. 1); this is mostly due to the fact that the Vidarbha region lies in the southwest quadrant of the area of tropical disturbances moving through the country during the monsoon season.

A number of water resources projects have been proposed for implementation in the Vidarbha region during the coming Five Year Plan schemes. Considering this, we analysed all the severe rainstorms of the Vidarbha region during the 100 yr period from 1891 to 1990, using the Depth-Area-Duration (DAD) method. The maximum average raindepths obtained for different areas and over different durations will be useful to the design engineers and hydrologists of this region for estimating probable maximum flood (PMF) values, which are required for the design of dam spillway capacities as well as for verifying and checking the spillway capacities of existing dams and reservoirs and for taking remedial measures where necessary.

2. Rainfall climatology of Vidarbha. Areawise, Vidarbha (about $97537 \mathrm{~km}^{2}$ ) is the second largest subdivision of Maharashtra State. The rainfall characteristics of this subdivision are governed to a large extent by its location in the central part of the country. The southwest or summer monsoon rainfall sets in over the Vidarbha region by about 10 June and withdraws by about the first week of October. Table 1 gives the mean monthly, seasonal and annual rainfall of the Vidarbha subdivision. The table shows that Vidarbha receives about $107 \mathrm{~cm}$ of rainfall annually, and that $88 \%$ of this falls during the monsoon months of June to September.

The highest amounts of rainfall recorded over periods of 1 day (' 1 -day rainfall') at long-term stations were identified from the 100 yr rainfall data. It was observed that the highest 1-day rainfall at the majority of stations ranged between 25 and $40 \mathrm{~cm}$. Table 2 lists the stations which had a maximum 1-day rainfall of $30 \mathrm{~cm}$ or more, along with their extreme raindepths (probable maximum precipitation, PMP). The table shows that the stations at Dharni and Ghorajheri recorded the highest 1-day rainfall, 40 and $41 \mathrm{~cm}$.

Knowledge of extreme 1-day rainfall at specific locations is useful in the planning and design of water resources projects for conservation of storm runoff and in designing waterways under bridges and culverts.

Table 1. Mean monthly, monsoonal (Jun-Sep) and annual rainfall, in $\mathrm{cm}$, over the Vidarbha subdivision

\begin{tabular}{|cccccccccccccc|}
\hline Jan & Feb & Mar & Apr & May & Jun & Jul & Aug & Sep & Oct & Nov & Dec & Jun-Sep Annual \\
\hline 1.1 & 1.4 & 1.3 & 1.1 & 1.2 & 16.4 & 32.5 & 25.9 & 19.0 & 4.6 & 1.8 & 0.8 & 93.8 & 107.1 \\
\hline
\end{tabular}


Table 2. Highest 1 -day rainfall $(>30 \mathrm{~cm}$ ) over the Vidarbha subdivision (1891 to 1990). PMP: probable maximum precipitation

\begin{tabular}{|lllcll|}
\hline Rainstorm & Station & District & $\begin{array}{c}\text { Highest 1-day } \\
\text { rainfall }(\mathrm{cm})\end{array}$ & $\begin{array}{c}\text { Date of } \\
\text { occurrence }\end{array}$ & $\begin{array}{c}\text { PMP } \\
(\mathrm{cm})\end{array}$ \\
\hline 1 & Deolgaon raja & Buldhana & 30.4 & 21 Aug 1903 & 59.0 \\
2 & Mehokar & Buldhana & 32.5 & 11 Sep 1892 & 62.7 \\
3 & Karanja & Akola & 30.0 & 27 Sep 1891 & 60.4 \\
4 & Telhara & Akola & 39.2 & 14 Sep 1959 & 80.2 \\
5 & Dharni & Amraoti & 41.1 & 25 Aug 1965 & 68.6 \\
6 & Hinganghat & Wardha & 31.2 & 18 Jul 1913 & 51.5 \\
7 & Nagpur & Nagpur & 31.4 & 12 Jun 1911 & 57.7 \\
8 & Parseoni & Nagpur & 31.8 & 12 Jul 1942 & 61.0 \\
9 & Umrer & Nagpur & 33.0 & 14 Aug 1953 & 58.3 \\
10 & Badalkasa & Bhandara & 37.5 & 31 Aug 1947 & 76.6 \\
11 & Khyrbund & Bhandara & 33.5 & 2 Sep 1961 & 69.8 \\
12 & Pangree & Bhandara & 39.5 & 25 Jul 1937 & 80.3 \\
13 & Sakoli & Bhandara & 38.3 & 26 Jun 1908 & 69.5 \\
14 & Pandharkawara & Yeotmal & 33.9 & 17 Aug 1963 & 73.8 \\
15 & Yeotmal & Yeotmal & 33.7 & 21 Jul 1937 & 61.5 \\
16 & Ahiri & Chandrapur & 31.9 & 14 Aug 1953 & 68.2 \\
17 & Armori & Chandrapur & 33.7 & 5 Sep 1910 & 69.9 \\
18 & Brahmpuri & Chandrapur & 32.3 & 31 Aug 1938 & 70.3 \\
19 & Chimur & Chandrapur & 33.5 & 9 Aug 1927 & 69.9 \\
20 & Gadchiroli & Chandrapur & 32.0 & 2 Aug 1908 & 61.5 \\
21 & Garmusi & Chandrapur & 31.2 & 13 Aug 1949 & 69.9 \\
22 & Ghorajheri & Chandrapur & 40.0 & 19 Jul 1959 & 72.5 \\
& & & & & \\
\hline
\end{tabular}

Examination of past synoptic situations has shown that heavy rainfall over the Vidarbha subdivision during the southwest monsoon season is mostly due to: (1) westward or west-northwestward movement of different cyclonic disturbances, i.e. depressions, lows, upper air cyclonic circulations, etc., over the Vidarbha subdivision, and (2) position and strength of the axis of the seasonal monsoon trough, especially when it is south of its normal position.

3. DAD analysis of severe rainstorms over Vidarbha. The Vidarbha subdivision consists for the most part of the river basins of 2 major rivers, viz. the Wardha and Wainganga, along with their tributaries. The drainage areas of these 2 rivers in Vidarbha are ca $46182 \mathrm{~km}^{2}$ and $37988 \mathrm{~km}^{2}$, respectively. These rivers become flooded during the monsoon season, causing extensive loss of life and destruction of

Table 3. Raindepths (cm) of severe rainstorms over Vidarbha for areas up to $50000 \mathrm{~km}^{2}$ and durations of (a) 1 day, (b) 2 days and (c) 3 days

\begin{tabular}{|c|c|c|c|c|c|c|c|c|c|c|c|}
\hline \multirow{2}{*}{$\begin{array}{l}\text { Storm } \\
\text { no. }\end{array}$} & \multirow[t]{2}{*}{ Period } & \multirow[t]{2}{*}{ Storm centre (District) } & \multicolumn{9}{|c|}{ Area $\left(\times 100 \mathrm{~km}^{2}\right)$ : } \\
\hline & & & Point & 1 & 5 & 10 & 50 & 100 & 250 & 300 & 500 \\
\hline \multicolumn{12}{|c|}{ (a) 1-day duration } \\
\hline 1 & 26 Jun 1908 & Sakoli (Bhandara) & 38.0 & 37.7 & 37.0 & 36.4 & 31.9 & 28.2 & 20.4 & 19.0 & 15.4 \\
\hline 2 & 4 Aug 1912 & Armori (Chandrapur) & 27.7 & 27.4 & 26.9 & 26.3 & 23.3 & 21.0 & 16.4 & - & - \\
\hline 3 & 17 Jun 1927 & Arvi (Wardha) & 29.1 & 28.7 & 28.2 & 27.5 & 22.1 & 17.8 & 13.7 & 12.9 & 10.5 \\
\hline 4 & 2 Jul 1930 & Wani (Yeotmal) & 36.0 & 35.6 & 33.5 & 31.5 & 22.1 & 18.8 & 16.0 & - & - \\
\hline 5 & 16 Jun 1936 & Umrer (Nagpur) & 20.0 & 19.9 & 19.7 & 19.5 & 17.8 & 16.7 & 15.4 & 15.0 & 13.5 \\
\hline 6 & 3 Aug 1953 & Brahmapuri (Chandrapur) & 30.5 & 29.5 & 27.7 & 27.0 & 20.0 & 17.9 & 16.5 & 16.2 & 15.2 \\
\hline 7 & 14 Aug 1953 & Ahiri (Chandrapur) & 32.0 & 31.5 & 31.0 & 30.6 & 26.8 & 23.8 & 17.8 & 16.2 & 13.5 \\
\hline 8 & 13 Aug 1986 & Rajura (Chandrapur) & 31.0 & 30.5 & 29.4 & 28.4 & 25.5 & 23.5 & 20.0 & 19.6 & 18.1 \\
\hline \multicolumn{3}{|c|}{ Envelope value } & 38.0 & 37.7 & 37.0 & 36.4 & 31.9 & 28.2 & 20.4 & 19.6 & 18.1 \\
\hline \multicolumn{12}{|c|}{ (b) 2-day duration } \\
\hline 1 & 25-26 Jun 1908 & Sakoli (Bhandara) & 43.0 & 42.7 & 42.2 & 41.2 & 36.4 & 31.8 & 24.3 & 23.2 & 20.3 \\
\hline 2 & 3-4 Aug 1912 & Armori (Chandrapur) & 51.9 & 51.4 & 50.8 & 49.8 & 44.4 & 40.4 & 32.7 & 30.5 & 24.0 \\
\hline 3 & $17-18$ Jun 1927 & Arvi (Wardha) & 37.7 & 37.2 & 35.8 & 34.2 & 26.2 & 23.2 & 19.5 & 18.7 & 16.1 \\
\hline 4 & 2-3 Jul 1930 & Wani (Yeotmal) & 71.3 & 69.7 & 61.0 & 56.0 & 37.1 & 32.0 & 26.1 & 24.9 & 20.6 \\
\hline 5 & $16-17$ Jun 1936 & Kunghari (Nagpur) & 36.0 & 35.9 & 35.6 & 35.3 & 33.4 & 31.2 & 28.4 & 27.6 & 24.6 \\
\hline 6 & 3-4 Aug 1953 & Brahmapuri (Chandrapur) & 44.9 & 44.0 & 41.8 & 40.0 & 33.1 & 29.2 & 25.2 & 25.0 & 23.9 \\
\hline 7 & 13-14 Aug 1953 & Ahiri (Chandrapur) & 47.2 & 47.0 & 46.5 & 45.8 & 40.5 & 36.2 & 27.9 & 26.0 & 21.0 \\
\hline 8 & 13-14 Aug 1986 & Rajura (Chandrapur) & 61.2 & 60.7 & 59.8 & 58.3 & 50.9 & 46.0 & 37.5 & 35.2 & 29.9 \\
\hline \multicolumn{3}{|c|}{ Envelope value } & 71.3 & 69.7 & 61.0 & 58.3 & 50.9 & 46.0 & 37.5 & 35.2 & 29.9 \\
\hline \multicolumn{12}{|c|}{ (c) 3-day duration } \\
\hline 1 & 25-27 Jun 1908 & Sakoli (Bhandara) & 46.3 & 46.2 & 46.0 & 46.0 & 42.5 & 38.4 & 29.0 & 28.0 & 23.8 \\
\hline 2 & 3-5 Aug 1912 & Brahmapuri (Chandrapur) & 57.9 & 57.9 & 57.8 & 57.7 & 55.0 & 51.6 & 42.0 & 39.0 & 31.1 \\
\hline 3 & $17-19$ Jun 1927 & Arvi (Wardha) & 38.4 & 38.1 & 36.6 & 35.1 & 28.4 & 25.8 & 22.9 & 22.2 & 20.2 \\
\hline 4 & $1-3$ Jul 1930 & Wani (Yeotmal) & 77.4 & 75.3 & 71.2 & 65.5 & 46.5 & 39.2 & 33.5 & 32.0 & 28.2 \\
\hline 5 & 15-17 Jun 1936 & Kunghari (Nagpur) & 39.4 & 39.2 & 39.0 & 38.9 & 35.9 & 32.2 & 29.8 & 29.1 & 28.0 \\
\hline 6 & $3-5$ Aug 1953 & Brahmapuri (Chandrapur) & 44.9 & 44.1 & 42.5 & 41.7 & 39.0 & 36.2 & 33.1 & 32.3 & 29.6 \\
\hline 7 & 13-15 Aug 1953 & Ahiri (Chandrapur) & 49.2 & 49.0 & 48.8 & 48.2 & 44.9 & 40.9 & 33.3 & 31.8 & 27.1 \\
\hline 8 & 12-14 Aug 1986 & Rajura (Chandrapur) & 66.2 & 65.5 & 64.4 & 62.8 & 54.8 & 49.0 & 40.9 & 39.8 & 37.2 \\
\hline \multicolumn{3}{|c|}{ Envelope value } & 77.4 & 75.3 & 71.2 & 65.5 & 55.0 & 51.6 & 42.0 & 39.8 & 37.2 \\
\hline
\end{tabular}


property and agricultural lands. In order to estimate probable maximum flood (PMF), it is essential to determine maximum average raindepths yielded by different rainstorms over the region.

Daily rainfall data from 100 to 150 long-term rainfall stations, uniformly distributed in and around the Vidarbha region, were used to analyse severe rainstorms for the period 1891 to 1990 . Examination of this data showed that during this 100 yr period, 8 extremely severe rainstorms affected this subdivision. These are listed in Table 3.

Fig. 1 shows where the heavy rain centres of some of these rainstorms were located. It should be noted that, even when heavy rain centres are located in this region, their isohyetal patterns may extend over the neighbouring regions (see Figs. 2 to 4 ). All these rainstorms were analysed using the standard DAD technique (WMO 1969, 1986). In this technique, a rainstorm is taken as a unit of study and a 3-dimensional relationship is determined between (1) average raindepth, (2) storm area and (3) a given duration of time. Using this technique, average raindepths were obtained for 1-, 2-, and 3-day periods during rainstorms for areas up to $50000 \mathrm{~km}^{2}$. However, it should be noted that all these rainstorms had an areal extent of more than $100000 \mathrm{~km}^{2}$.

The DAD data for 1-, 2- and 3-day periods are given in Table 3 . The data show that out of 8 severe rainstorms which affected this region, 4 rainstorms occurred in the month of August, 3 in June and 1 in July. The highest rainfall recorded over a 1-day period occurred in June 1908 (i.e. $38 \mathrm{~cm}$ ) and for 2- and 3-day periods the maximum values were recorded during the July 1930 rainstorm, with point rainfall values of 71 and $77 \mathrm{~cm}$ respectively. It was also observed that the August 1986 rainstorm contributed the highest raindepths for areas $>25000 \mathrm{~km}^{2}$ over 1 - and 3 -day periods and for areas $>1000 \mathrm{~km}^{2}$ over 2 -day periods. The rainstorms producing envelope raindepths over 1-, 2- and 3-day periods were as follows:

$$
\begin{aligned}
& \text { over 1-day periods: } \leq 25000 \mathrm{~km}^{2} \quad \text { Jun } 1908 \\
& \leq 50000 \mathrm{~km}^{2} \quad \text { Aug } 1986 \\
& \text { over 2-day periods: } \leq 500 \mathrm{~km}^{2} \quad \text { Jul } 1930 \\
& \leq 50000 \mathrm{~km}^{2} \quad \text { Aug } 1986 \\
& \text { over 3-day periods: } \leq 1000 \mathrm{~km}^{2} \quad \text { Jul } 1930 \\
& \leq 25000 \mathrm{~km}^{2} \quad \text { Aug } 1912 \\
& \leq 50000 \mathrm{~km}^{2} \quad \text { Aug } 1986
\end{aligned}
$$

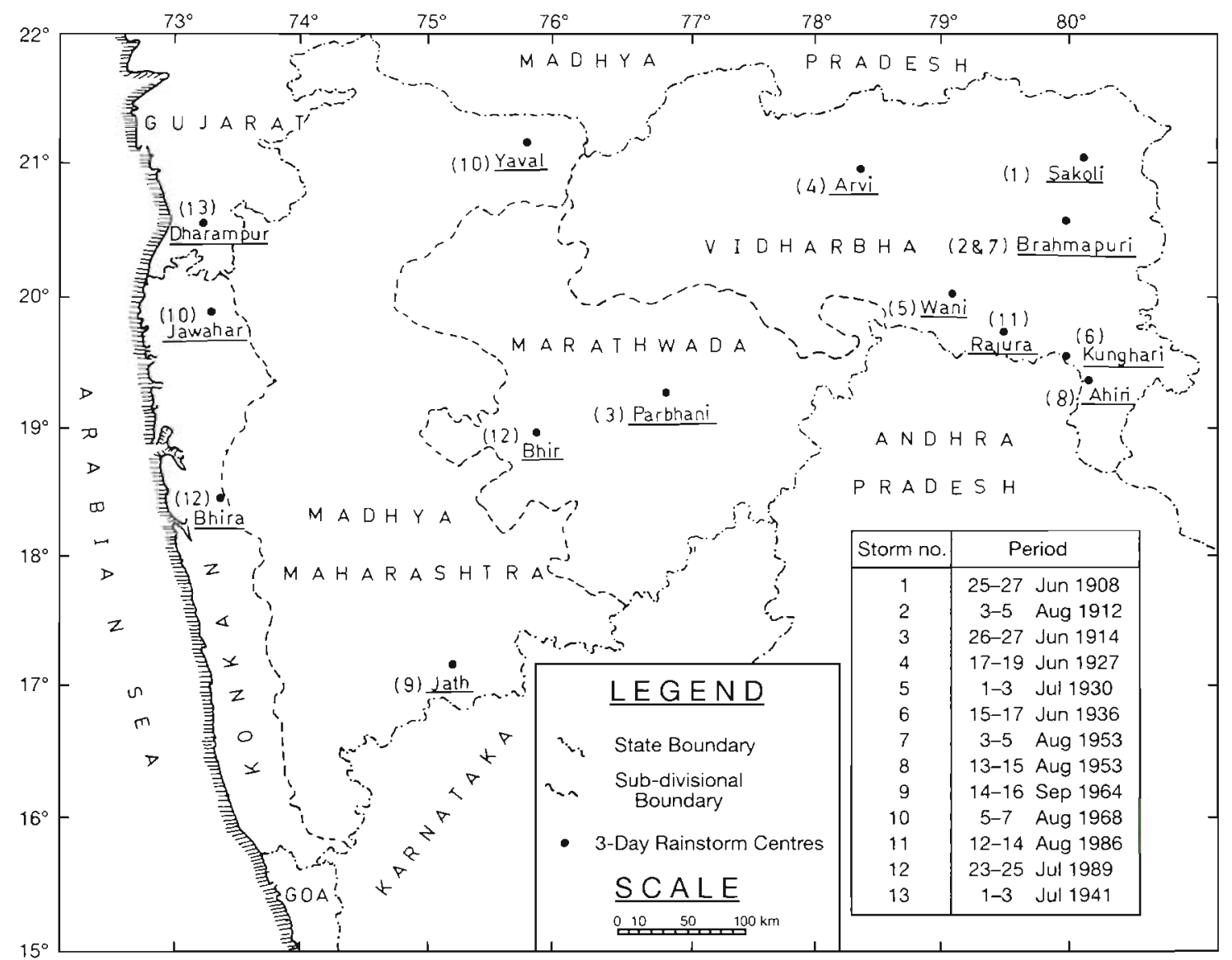

Fig. 1. Maharashtra, India, showing 3-day rainstorm centres over the plain area and coastal region of the state 
Figs. 2,3 \& 4 give the 3-day isohyetal patterns of severe rainstorms of June 1908, July 1930 and August 1986, respectively. The DAD raindepths thus obtained for 1-, 2-and 3-day periods (see Table 3) can be utilized to obtain design storm estimates for water resources projects in the Wardha and Wainganga river basins of the Vidarbha subdivision

4. Relationship between central and areal rainfall. Often, design engineers have to provide preliminary estimates of maximum rainfall at short notice for the design of hydraulic structures. The conventional methods of rainstorm analysis, referred to in Section 3, over and near the basin under study are time-consuming and require detailed analysis of past rainfall data before any final estimates can be given. In view of this, the relationship between central rainfall and its areal extent for the most severe rainstorms over the north Indian plains has been studied by Raman \& Chhabra (1966) and Dhar \& Bhattacharya (1977). Using their technique, an attempt was made here to establish a relationship between central rainfall and the average maximum raindepths of different areas obtained during severe rainstorms in Vidarbha.

The DAD raindepths of severe rainstorms given in Table 3 for 1-, 2-and 3-day durations were expressed as percentages of the point rainfall values for each standard area. The mean percentage raindepths thus obtained for all the severe rainstorms were used for further analysis.

4.1. Log-linear relationship: It was observed that the percentage ratios obtained for all the severe rainstorms of Vidarbha differed among the different durations (1. 2 and 3 days). An attempt was therefore made to verify whether the linear equation given below was valid for these percentage ratios:

$$
Y=100-k A^{n}
$$

where $Y$ is the percentage ratio of the average maximum rainfall over an area $A$ to the central rainfall of the storm and $k$ and $n$ are constants. $k$ and $n$ were evaluated by the least squares method and are as follows:

\begin{tabular}{lcc} 
Duration & $k$ & $n$ \\
\hline 1 day & 0.0926 & 0.6153 \\
2 days & 0.0738 & 0.6325 \\
3 days & 0.0333 & 0.6964
\end{tabular}

The goodness-of-fit of Eq. (1) for all 3 durations using the Chi-square test showed that the equation was statistically significant at the $99.5 \%$ level. Using this relationship, scatter diagrams (Fig. 5) were prepared to

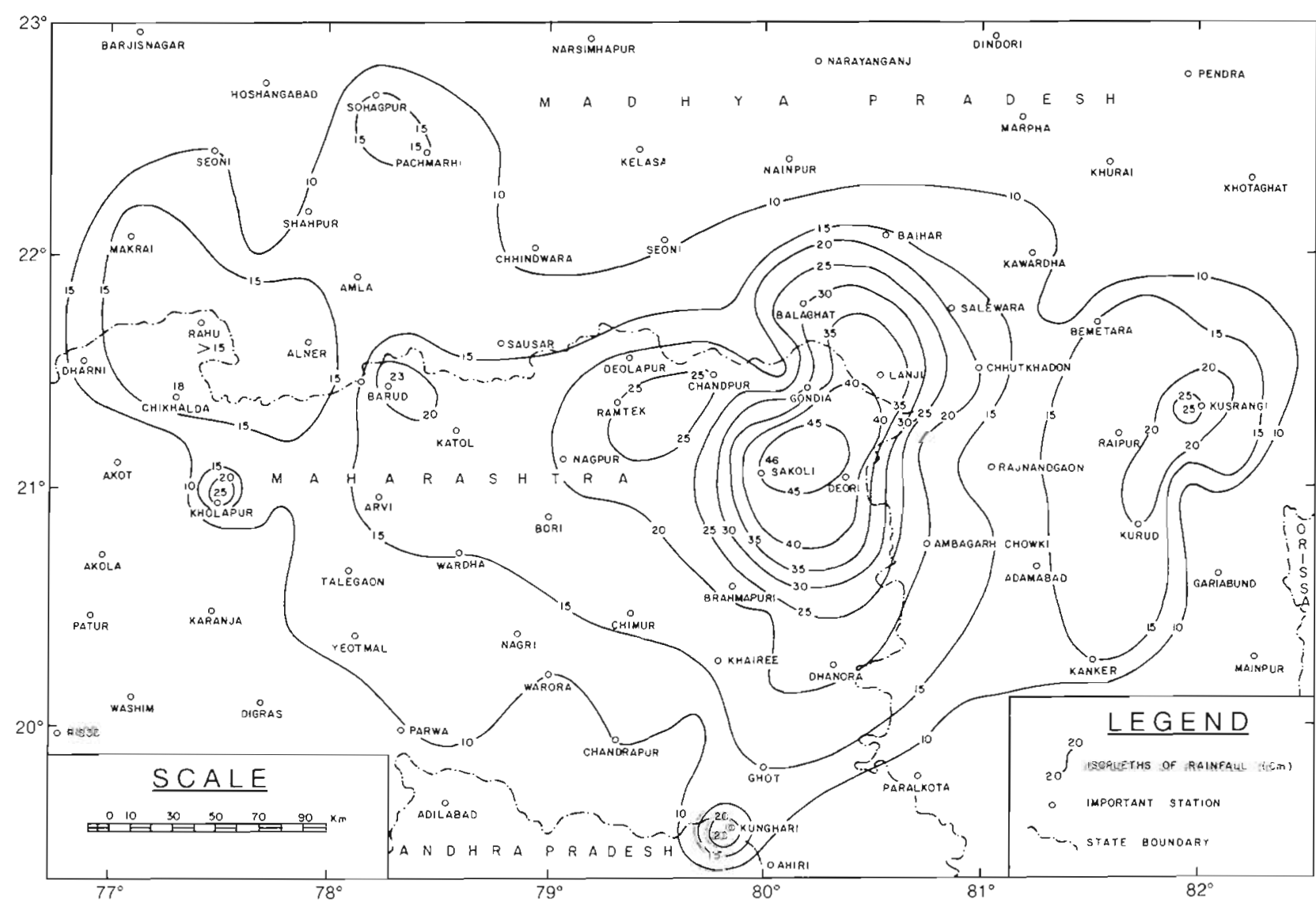

Fig. 2. The 3-day isohyetal pattern of the 25-27 June 1908 rainstorm over Maharashtra and neighbouring areas 


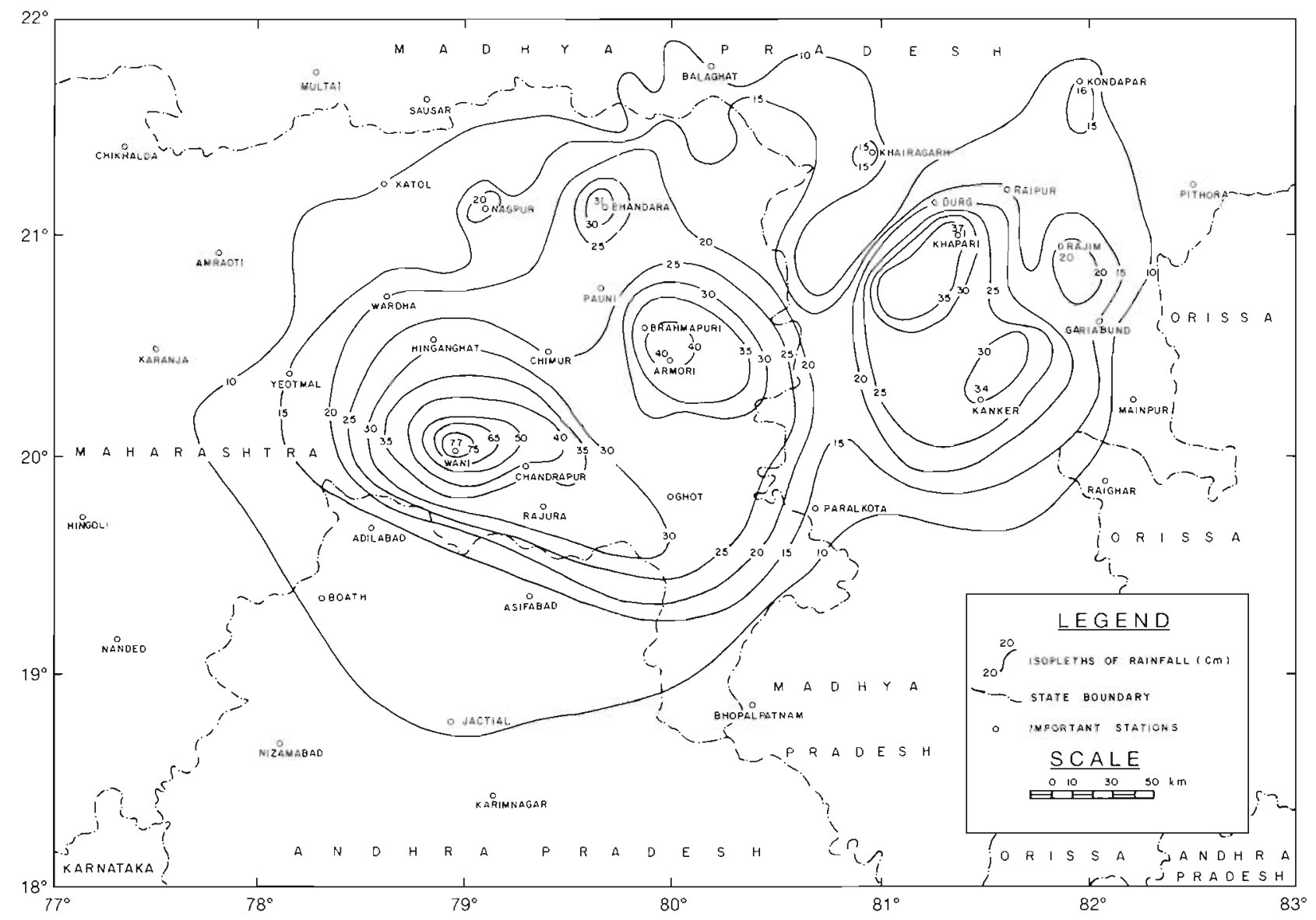

Fig. 3. The 3-day isohyetal pattern of the 1-3 July 1930 rainstorm over Maharashtra and neighbouring areas

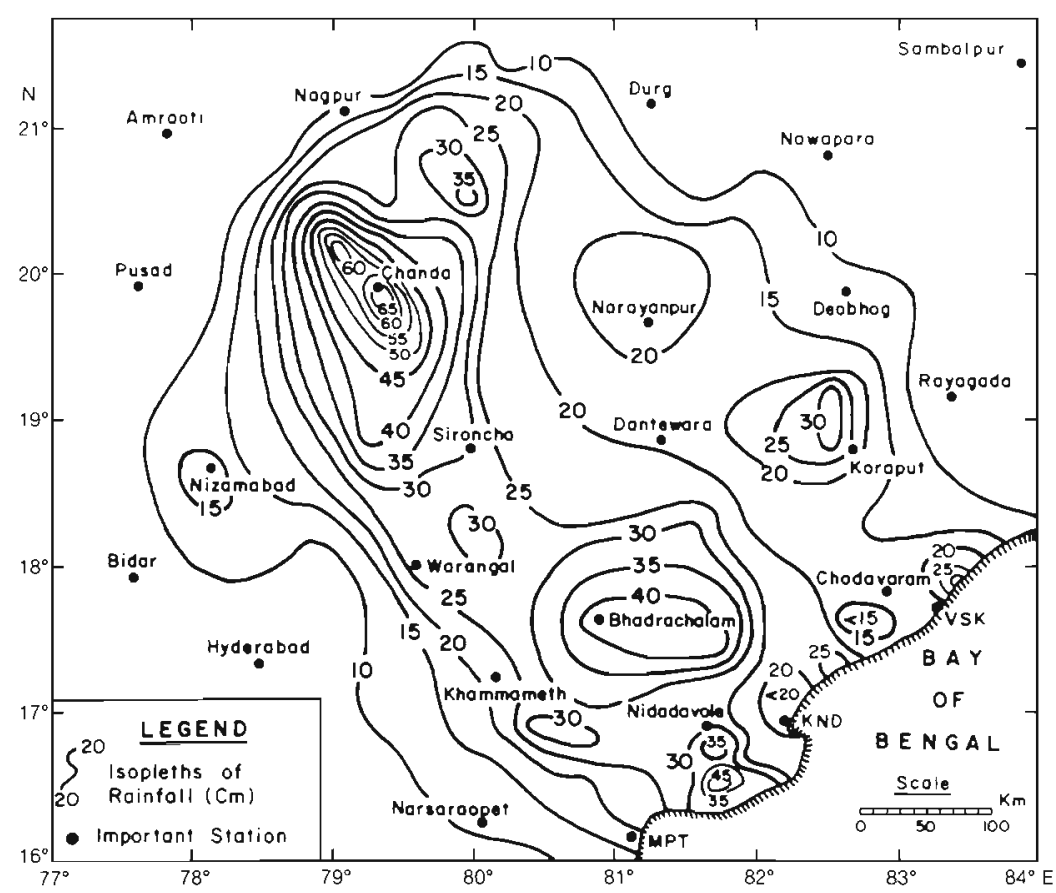

Fig. 4. The 3-day isohyetal pattern of the 12-14 August 1986 rainstorm over Maharashtra and neighbouring areas show the nature of the relationship between observed and estimated percentage values for 1 - to 3 -day durations. Fig. 5 shows that there is a oneto-one correspondence between the observed and estimated percentage values for areas $\leq 25000 \mathrm{~km}^{2}$, while for larger areas (i.e. lower percentage ratios) the correspondence is not as close. Therefore, for larger areas, this equation does not give correct estimates of the average maximum raindepths.

4.2. Exponential relationship: In order to obtain a general equation which was valid for both large and small areas, another type of equation was used by Horton (1924). According to him, the relationship between percentage values of rainfall and rainstorm areas could be expressed in the following exponential form:

$$
Y=100 e^{-k A^{n}}
$$



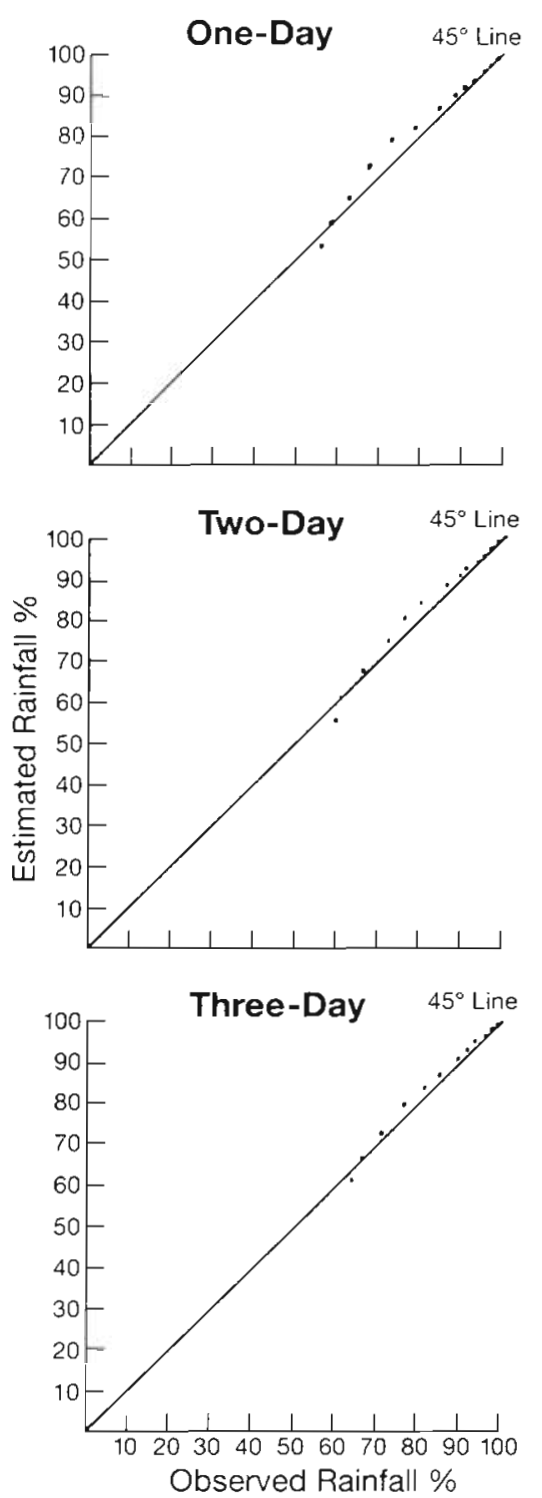

Fig. 5. Relationship between observed and estimated rainfall values using the log-linear equation

The symbols in Eq. (2) have the same meaning as in Eq. (1). $k$ and $n$ were evaluated by the least squares method and are as follows:

\begin{tabular}{lcc} 
Duration & $k$ & $n$ \\
\hline 1 day & 0.000635 & 0.673306 \\
2 days & 0.000533 & 0.688303 \\
3 days & 0.000254 & 0.742529
\end{tabular}

The goodness-of-fit of Eq. (2) for all 3 durations using the Chi-square test showed that these equations were statistically significant at the $99.9 \%$ level. Scatter diagrams were prepared (see Fig. 6) to compare the values estimated using Eq. (2) with observed values
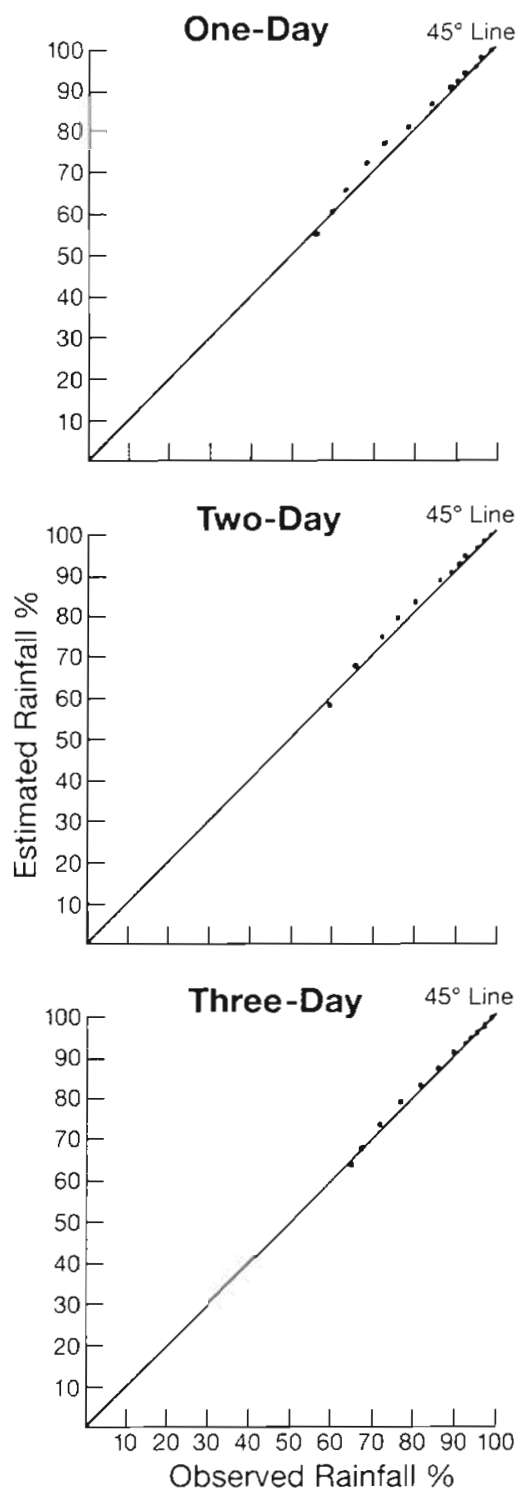

Fig. 6. Relationship between observed and estimated rainfall values using the exponential equation

for 1-, 2- and 3-day durations of rainstorms in Vidarbha. It can be seen in Fig. 6 that practically all the points lie on a straight line, forming a $45^{\circ}$ angle, and even points for larger areas (i.e. lower percentage values) have a better one-to-one correspondence as compared to those in Fig. 5.

Thus we conclude that the relationship between the areal-to-point percentage values and area of rainstorms for 1- to 3-day durations is exponential, as far as storms in Vidarbha are concerned, and that Eq. (2) gives better estimates of areal rainfall than Eq. (1).

5. Summary and conclusion. The following broad conclusions can be drawn from this study: 
(1) The mean annual rainfall of the Vidarbha subdivision is ca $107 \mathrm{~cm}$. The highest 1 -day rainfall $(41.1 \mathrm{~cm})$ was recorded at Dharni.

(2) Examination of 100 yr daily rainfall data from 1891 to 1990 revealed that the Vidarbha subdivision experienced 8 extremely severe rainstorms. These rainstorms were analysed using the DAD technique, and maximum average raindepths of these rainstorms from point to $50000 \mathrm{~km}^{2}$ were recorded in this study for 1- to 3-day durations.

This analysis showed that the rainstorms yielding the greatest raindepth for 1-day duration were in June 1908 and August 1986; for 2-day duration, in July 1930 and August 1986; and for 3-day duration, in July 1930 , August 1912 and August 1986. The raindepths obtained from these rainstorms can be utilized for PMP study, preparation of PMP generalized charts and/or the preparation of design storm estimates for the Vidarbha region.

(3) The average maximum raindepths obtained over different areas from the severe rainstorms of Maharashtra, expressed as a percentage of central rainfall for different durations, can be estimated fairly accurately using an exponential equation of the form $Y=100 \mathrm{e}^{-k A^{n}}$. This study has shown that this equation gives better estimates of areal raindepths, for small as well as large areas, over 1 - to 3 -day durations of rainstorms in Vidarbha.

Editor: V. Meentemeyer, Athens, Georgia, USA
Acknowledgements. The authors are grateful to Prof. R. N. Keshavamurty, Director, I.I.T.M., Pune, for providing necessary facilities for completing this study. Thanks also to Dr G. B. Pant, Deputy Director and Head, Climatology and Hydrometeorology Division, and Dr O. N. Dhar, Emeritus Scientist, for their encouragement and valuable suggestions in improving this paper.

\section{LITERATURE CITED}

Dhar ON, Bhattacharya BK (1977) Relationship between central rainfall and its areal extent for severemost rainstorms of north Indian plains. J Irrig Power 28(2):245-250

Dhar ON, Kulkarni BD, Nandargi SS (1989) Hydrometeorological studies of Maharashtra rainfall - a brief appraisal. In: Proc 3rd National Symp on Hydrology, held at CWPRS, Pune during 5-7 July 1990, Vol I, Sec V. CWPRS, Pune Publ, p 217-226

Horton RE (1924) Discussion on distribution of intense rainfall. Trans Am Soc Civ Eng 87:578-585

Kulkarni BD (1991) Hydrometeorological studies of Maharashtra rainfall. MSc thesis, University of Poona

Raman PK, Chhabra BM (1966) An emprirical relationship between average rainfall and areal extent for major rainstorms of Bihar and Madhya Pradesh. Proc Symp on Hydrometeorology of India with special reference to flood forecasting and warning. Ind J Meteorol 17(Spec Issue):97-102

WMO (World Meteorological Organization) (1969) Manual for depth-area-duration analysis of storm precipitation. WMO No. 237, TP 129. WMO, Geneva

WMO (World Meteorological Organization) (1986) Manual for estimation of Probable Maximum Precipitation (PMP). Operational hydrology, Rep No. 1, 2nd edn. WMO No. 332, WMO, Geneva

Manuscript first received: August 18, 1995

Revised version accepted: November 15, 1995 